To cite this Article: Ojasalo, K. (2017) Designing a service-dominant business model in the industrial context. In Satu Miettinen (Ed.) An Introduction to Industrial Service Design. New York : Routledge, 117-123. 


\section{Designing a service-dominant business model in the industrial context}

\section{Katri Ojasalo}

This chapter introduces a comprehensive, easy-to-use tool for designing a customercentered business model in the industrial context. This tool can help industrial companies implement their service-dominant strategies and facilitate their customers' value creation. When used in a service design process, this business model tool helps industrial companies better utilize the deep insight of their business customers and design integrated solutions to correspond their customers' future needs.

\section{Why service-dominant business tools are needed also in the industrial context?}

Many industrial companies have recently faced the question of how to improve the profit margin. At the same time, their customers are increasingly demanding turnkey solutions instead of products that partially solve their problems. Consequently, industrial companies have started to design integrated solutions to their customers' problems to differentiate themselves from competitors and to create competitive advantage. This kind of logic of focusing on industrial service growth is compelling: new business with current customers tends to create higher customer loyalty, new unique selling points, hence higher margins, and enable a higher speed of innovation.

However, adopting the role of a service provider is often demanding because an industrial service business model requires a very different approach than a pure manufacturing business model. While a pure manufacturing business model concentrates on selling products, a service approach focuses on facilitating the customers' value creation and co-creating value with them. The customers might not value the proposed service models if they cannot see clear added value to the current co-operation. Thus, industrial service providers need a wide range of competencies to handle both product and service aspects of their offerings (Ojasalo, 2007).

When industrial companies become facilitators and value co-creators they deeply engage themselves in their customers' processes. Adopting this kind of service-dominant business logic means that the industrial company has to constantly search for possibilities to understand and support the customers' value creation processes (e.g. Grönroos and Ravald, 2011). Consequently, a more holistic understanding of the 
customer's business, processes, practices and experiences is needed. This requires that companies build their businesses on an in-depth insight into customers' activities and context, and analyze what implications these have for their business (see Heinonen et al., 2010).

However, most companies still operate in terms of traditional industrial logic that highlights the supplier company's process as primary. The reason for this may not always be ignorance of the emerging service-dominant business thinking. In fact, managers and developers still have too few tools to implement customer-centered, service-dominant strategies (Ojasalo \& Ojasalo, 2015). Popular business tools that direct companies' planning and decisions are mostly based on the traditional industrial logic: "we are selling something to someone". There is a clear need for tools that truly help industrial companies develop their business models to meet their customers' everyday processes and problems: "how can we create new value together with our customers?"

\section{Service Logic Business Model Canvas covering both the value captures and value creation}

The Service Logic Business Model Canvas (Ojasalo \& Ojasalo, 2015) responds to the above need by covering both the industrial company's viewpoint (value capture) and its customer's viewpoint (value creation). This tool makes industrial service designers systematically consider the customer viewpoint and their everyday business and processes in each element of the business model. The testing of this tool in several company settings shows that the Service Logic Business Model Canvas is a relevant and easy-to-use tool that can help companies implement customer-centered strategies focusing on customer value creation. The development process of the canvas took over 18 months and more than 100 persons and 70 companies were involved in the process (Ojasalo \& Ojasalo, 2015).

Like the original Business Model Canvas (Osterwalder and Pigneur, 2010), the Service Logic Business Model Canvas is composed of nine building blocks (see Figure 1). In each block of the canvas, both the industrial service provider viewpoint ("From our point of view") and the customer viewpoint ("From a customer point of view") are considered. The customer viewpoint makes industrial service designers analyze their business and offering from the perspective of their customers' goals, practices and experiences. Thus, 
the process of how to design a service-dominant business model also needs to be more customer-centered, and various service design (and foresight) methods should be used for information gathering, ideation, and development work (see Ojasalo et al., 2015). In other words, the effective application of the Service Logic Business Model Canvas requires plenty of customer information that can be generated with the help of various service design methods before starting to fill in the canvas. The canvas is then best filled in a co-design workshop where the customer data is processed together with various stakeholders. Next, the contents of the Service Logic Business Model Canvas are briefly shown.

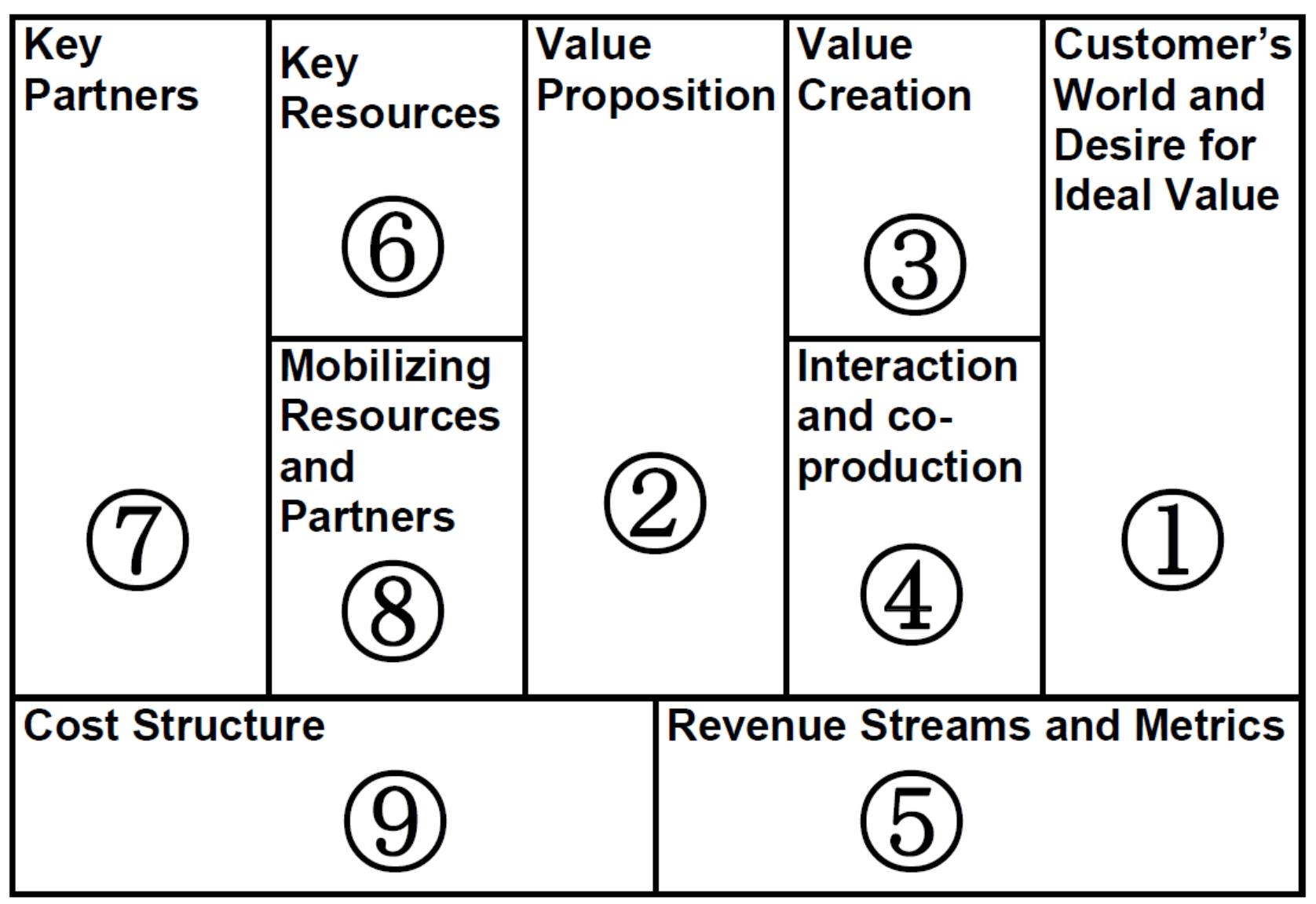

Figure 1. Service Logic Business Model Canvas (based on Ojasalo \& Ojasalo, 2015, 321)

\section{Customer's World and Desire for Ideal Value}

The first block (1) to be filled in during a co-design session is called "Customer's World and Desire for Ideal Value". In other words, before moving to the value proposition and other blocks of a business model, it is essential to deeply discuss the customer's (and 
the customer's customer's) business to get a holistic understanding of the customer's world: context, activities, practices, experiences etc. In this block, the customer's explicit and latent problems and motivations as well as the goals and benefits that the customer desires are analyzed. In addition to functional and economic benefits, customers may also value emotional, social, ethical, environmental and symbolic aspects. The information of this block is often based on the customer personas created during a service design process. The personas illustrate typical customer profiles and they are often based on the data generated in interviews, observations, probes, workshops, etc. The questions to be answered in the first block include: - How do we get a deep insight and holistic understanding of the customers' worlds, their future strategies, and their own customers' world? $\bullet$ Why do the customers buy? $\bullet$ What kind of benefits (functional, economic, emotional, social, ethical, environmental, symbolic) do the customers desire?

\section{Value Proposition}

The second block (2) of the canvas is "Value proposition" that suggests what impacts customers can expect from the offering of the industrial company. The value proposition should naturally be based on the customer insight described in the previous "Customer's world" block. The value proposition highlights the importance of capturing what the customer really buys when the industrial company sells its solution. The industrial company's offering should correspond with the customer's mental model of what the customer intends to get and achieve with the offering. The questions to be answered include: • What value are we selling? • What are the elements of our offering? • What is unique in our offering? $\cdot$ What value is the customer buying? $\bullet$ What are the elements of the customer needing? $\bullet$ Which of the customer's challenges and problems need to be solved?

\section{Value Creation}

The third block (3), "Value creation", shows how the industrial company's world is related to its customer's world, and how its offering becomes embedded in the customer's context, activities, practices, and experiences. Here, the industrial company analyzes the possibilities to facilitate customers' value creation and how they can help 
their customers reach their goals identified in the first block ("Customer's world"). From the customer's point of view, it is important to analyze how value emerges in customer's practices and how the customer achieves the long-term benefits through their own processes. Here, the focus is on the analyzing how the value is created in the customers' everyday business and how the industrial company is able to facilitate its customers' value creation. The questions to be answered include: - How is our offering embedded in the customer's world? • How can we facilitate the customers to reach their goals? • How does the value emerge in customer's practices? • How are customer's longterm benefits accomplished?

\section{Interaction and co-production}

The fourth block (4), "Interaction and co-production", focuses on the customer's participation in the industrial company's activities and utilization of its resources. Here, the key questions relate to how to facilitate the interaction between the industrial company and its customer and what the customer's mental models of interacting with the industrial company are. In addition, customers' activities and their different use contexts are analyzed here. The questions to be answered include: - How can we support customer co-production and the interaction between us and the customer? • What are the customer's activities during the use and different use contexts? $\bullet$ What are the customer's mental models of interacting with us?

\section{Revenue Streams and Metrics}

In the fifth block (5), "Revenue Streams and Metrics", the industrial company's earnings logic, financial feedback and other benefits are identified. This block also focuses on analyzing for which benefits the customer is willing to pay. The price is linked to customer value rather than costs. This block also indicates the key performance indicators that verify the value created for the industrial company and its customer. The questions to be answered include: - What is our earnings logic and how is our financial feedback generated? • How can we apply customer value-based pricing? • What else valuable do we get other than money? - What are the key performance metrics of our business success? $\bullet$ For which benefits is the customer actually willing to pay and how? 
What is the financial value to the customer? What are the key performance indicators of the customer's business and how are we following them?

\section{Key Resources}

The sixth block (6), "Key Resources", focuses on the dynamic, often intangible resources related to the value proposition in question. Especially, the core competences as key resources are highlighted. In service-dominant business, the customer is an important resource, and consequently the customer's knowledge and skills should also be analyzed. The questions to be answered include: - What skills and knowledge do we need - also from the customers and other stakeholders? $\bullet$ What other material and immaterial resources and tools are required?

\section{Key Partners}

The seventh block (7) identifies the "Key Partners" and analyzes those partners beyond an industrial company-customer relationship that are directly required in value creation Here, roles related to value creation, the resources needed and the benefits generated are analyzed., The questions to be answered include: - Who are our key partners and what their roles? $\bullet$ How do the partners benefit from the cooperation? $\cdot$ How does the customer experience our partners? $\bullet$ What kind of partnerships does the customer have and how should they be taken into account?

\section{Mobilizing Resources and Partners}

The eighth block (8), "Mobilizing Resources and Partners", focuses on the utilization and development aspects of resources and partners and indicates how knowledge and skills are generated by all the stakeholders. This block stresses the integration of resources, which is a central activity of all stakeholders involved in business relationships. The questions to be answered include: - How do we coordinate multi-party value creation? • How do we utilize and develop partners and resources? $\bullet$ How can the customer utilize and develop partners and resources?

\section{Cost Structure}

In the ninth block (9), the "Cost Structure" of the business model is discussed. In addition to analyzing the industrial company's costs and other sacrifices inherent in the 
business model, the costs and other sacrifices induced for the customer are analyzed. The questions to be answered include: - What are the costs inherent in our business model? $\bullet$ What are our other sacrifices? - How would potential cost cuttings impact customer value and experience? $\bullet$ What costs and other sacrifices are required from the customer?

\section{The benefits of using the Service Logic Business Model Canvas}

There is a clear need for managerial approaches that actually help industrial companies develop business models based on a deep understanding of customers' (and customer's customer's) contexts. The Service Logic Business Model Canvas responds to this need. It makes its users systematically consider the customer's business in each element of the business model.

Most business model tools address customer needs and value as one of the elements addressed. In comparison, the Service Logic Business Model Canvas brings customers' needs, value and contexts into the center of the business model. In addition, it relates the customer viewpoint to the industrial company's viewpoint, thus enabling the design of a realistic business model that can be implemented. The testing of the tool in various companies shows that the Service Logic Business Model Canvas is a relevant, easy-to-use and simple tool that can help companies implement the customer-centered business strategies. The tool highlights the importance of deep customer insight, and it is designed to be applied to each customer profile separately. By using the framework individually to each relevant customer profile, it is possible to have a deeper understanding of the customer logic of each profile. A separate business model with all its elements is designed to each customer profile.

The Service Logic Business Model Canvas functions both as a rapid prototype of a new business model and as a communication tool that quickly shows the company's current (or future) business model. If used in workshops with various manager and employee groups of the industrial company, the canvas can also function as a discussion tool for creating a more customer-centered business culture. It makes people put the customer in the center of all the elements of a business model. 


\section{References}

Grönroos, C. and Ravald, A. (2011) $)_{L^{-}}$Service as business logic: implications for value creation and marketing. J ournal of Service Management, 22(1), 5-22.

Heinonen, K., Strandvik, T., Mickelsson, K-J, Edvardsson, B., Sundström, E. and Andersson P. (2010) $)_{L^{-}}$A Customer Dominant Logic of Service. J ournal of Service Management, 21(4), 531-548.

Ojasalo, K. (2007), Developing Industrial Services - An Empirical Study, The Business Review, Cambridge, Vol. 7 No. 1, pp. 58-62.

Ojasalo, K., Koskelo, M. and Nousiainen, A.K. (2015), Foresight and service design boosting dynamic capabilities in service innovation. In Agarwal, R., Selen, W., Roos, G. and Green, R. (Eds.), The Handbook of Service Innovation. London, UK: Springer-Verlag, 193-212.

Ojasalo, K. and Ojasalo, J. (2015), Adapting Business Model Thinking to Service Logic: An Empirical Study on Developing a Service Design Tool. In Gummerus J . and von Koskull K. (Eds. ), The Nordic School - Service Marketing and Management for the Future. CERS, Hanken School of Economics, Helsinki, Finland, 309-333.

Osterwalder, A. and Pigneur, Y. (2010). Business model generation: A handbook for visionaries, game changers, and challengers. Hoboken, NJ : Wiley. 